\title{
Dietary Intake of New Zealand European and Pacific Woman from the PROMISE Study ${ }^{\dagger}$
}

\author{
Nikki Renall 1,2, Jo Slater ${ }^{1}$, Rozanne Kruger ${ }^{1}$, Marilize Richter ${ }^{1}$, Gerald Tannock ${ }^{2,3}$ and \\ Bernhard H. Breier 1,2,* \\ 1 School of Sport, Exercise and Nutrition, College of Health, Massey University, Auckland 0632, \\ New Zealand; n.renall@massey.ac.nz (N.R.); j.s.slater@massey.ac.nz (J.S.); r.kruger@massey.ac.nz (R.K.); \\ m.richter@massey.ac.nz (M.R.) \\ 2 Riddet Institute, Centre of Research Excellence, Massey University, Palmerston North 4474, New Zealand; \\ gerald.tannock@otago.ac.nz \\ 3 Department of Microbiology and Immunology, University of Otago, Dunedin 9016, New Zealand \\ * Correspondence: b.breier@massey.ac.nz; Tel.: +64-9-414-0800 (ext. 43652) \\ + Presented at the 2018 Nutrition Society of New Zealand Annual Conference, Auckland, New Zealand, \\ 28-30 November 2018.
}

Published: 12 March 2019

Background: New Zealand is culturally diverse and has one of the highest rates of obesity in the world, especially among women. Which necessitates further exploration to investigate the relationship between the dietary intake of New Zealand women from different ethnicities, with different body compositions and metabolic disease risk.

Methods: Pacific (PI) and NZ European (NZE) women aged 18-45 years from Auckland participated in this cross-sectional study. They were included if they had either a normal body mass index (BMI) (NB: $>18.5$ and $\left.\leq 24.9 \mathrm{~kg} / \mathrm{m}^{2}\right)$, or an obese BMI $\left(\mathrm{OB}: \geq 30 \mathrm{~kg} / \mathrm{m}^{2}\right)$. Participants completed a 5-day non-consecutive estimated food record, anthropometric measurements (e.g., weight, height and \% body fat (DXA)), and provided fasting blood samples (e.g., HbA1c and lipid profile).

Results: In total 261 participants, 112 PI (OB $n=75$, NB $n=37$ ) and 149 NZE (OB $n=71$, NB $n=$ 78) completed the study. There were significant differences in mean $\mathrm{BMI} \mathrm{kg} / \mathrm{m}^{2}$ between PI-OB and NZE-OB $(p=0.024)$, and PI-NB and NZE-NB $(p=0.001)$. No significant differences between the four groups were observed in mean \pm SEM daily intake of energy $(\mathrm{kJ})$, protein $(\mathrm{g})$, total fat $(\mathrm{g})$, or total sugar (g). However, PI-NB and PI-OB consumed significantly more carbohydrate $(214.85 \mathrm{~g} / \mathrm{day}$ and $212.93 \mathrm{~g} /$ day respectively) compared to NZE-OB (183.94 g; $p=0.015)$, and NZE-NB (177.39 g, $p<$ 0.001). NZE women had a higher mean daily intake of caffeine ( $\mathrm{mg}$ ) and alcohol (g) compared to PI (both $p<0.001)$. NZE-NB consumed significantly more dietary fibre $(25.90 \mathrm{~g} /$ day; $p<0.001)$ compared to NZE-OB (22.10 g/day), PI-OB (18.29 g/day) and PI-NB (19.38 g/day), and NZE-OB consumed significantly more dietary fibre in comparison to PI OBMI and PI NBMI $(p=0.001)$.

Conclusions: PI and NZE women showed significant differences in carbohydrate and dietary fibre intake. Further analysis will explore which foods contributed to the variations in nutrient intakes between groups, and associations with body composition and metabolic disease risk will be investigated.

Supplementary Material: The poster is available online at www.mdpi.com/2504-3900/8/1/31/s1.

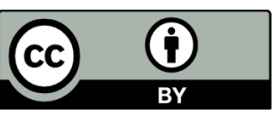

(C) 2019 by the authors. Licensee MDPI, Basel, Switzerland. This article is an open access article distributed under the terms and conditions of the Creative Commons Attribution (CC BY) license (http://creativecommons.org/licenses/by/4.0/). 